\title{
Trace elements in total atmospheric suspended particles in a suburban area of Paris: A study carried out by INAA
}

\author{
G. Lepetit, J.P. Deschamps and J. Moro
}

\author{
Commissariat à l'Énergie Atomique, Direction lle-de-France, Département Analyse \\ Surveillance Environnement, Service Radioanalyses Chimie Environnement, \\ BP. 12, 91680 Bruyères-le-Châtel, France
}

\begin{abstract}
The atmospheric particulate matter of industrialised cities have become a mixture of potentially basic substances whose concentration have to be monitored to assess the pollution levels. Anthropogenic elements, particularly trace metal, are part of these pollutants and the knowledge of their total concentration in the air is necessary to evaluate the pollution risk in term of maximum levels and long term exposure. In the present work a preliminary study initiated for monitoring the trace element levels present in total atmospheric suspended particles (TSP) of the suburban areas of Paris in France is presented. More than 30 elements have been determined using a high volume air sampler, about $600 \mathrm{~m}^{3} \cdot \mathrm{h}^{-1}$, installed near a busy highway and equipped with large filters for weekly collection of atmospheric aerosols. The study covers a period of a whole year (1998) and different weather conditions. Instrumental Neutron Activation Analysis (INAA) from the OSIRIS research reactor (neutron flux : $1.2 .10^{14} \mathrm{n} \cdot \mathrm{s}^{-1} \cdot \mathrm{cm}^{-2}$ ) at the Commissariat à l' Energie Atomique, Saclay centre, has been used for the determination of the great part of element whereas ICP-MS has been employed for determination of lead. Enrichment factors were used to investigate trends, emission sources.
\end{abstract}

\section{INTRODUCTION}

Atmospheric pollution is a major concern world-wide, in particular for the inhabitants of certain large urban areas. Its many and varied components attack the environment and health directly or indirectly. The primary contributions to atmospheric pollution in the form of solid zerosols come from either natural sources such as redispersion of crustal material, volcanic eruptions, aerosols of marine origin and pollens or from anthropogenic sources such as combustion of fuel oil and coal, combustion of fuels related to vehicular traffic, and various emissions related to industrial and human activities. It is generally accepted that the level in the atmosphere of particulate matter of natural origin is less than $10 \mu \mathrm{g} \cdot \mathrm{m}^{-3}$. In urban areas with high population density, such as the great megalopolises in developing countries, the concentrations in the atmosphere are regularly higher than the guideline values recommended by the World Health Organisation (WHO), which considers that the annual mean concentration should not exceed $60 \mu \mathrm{g} . \mathrm{m}^{-3}$. The long-term effects on health of a high concentration of atmospheric particulates, specifically the fraction smaller than $10 \mu \mathrm{m}$, are serious and insidious; moreover, the quantification of metals and certain anthropogenic trace elements present in the particulate matter is necessary in order to evaluate the hazards of the atmospheric pollution in terms of long-term exposure of the population and consequently implement the means to combat them and reduce them.

The preliminary study described here focuses on neutron activation analysis (INAA) of trace elements in atmospheric particulate matter collected using a very high flow rate (approximately $600 \mathrm{~m}^{3} \cdot \mathrm{h}^{-1}$ ) atmospheric sampling system fitted with a large filter. Weekly samples of approximately $100,000 \mathrm{~m}^{3}$ of filtered air, collected during 1998 near Paris, were used to determine the amplitude of seasonal fluctuations in pollutant concentrations, evaluate the enrichment factor of specific elements in the total atmospheric suspended particles (TSP) and, if possible, identify the origin of certain pollution sources.

\section{SITUATION}

The Service Radioanalyse Chimie Environnement (SRCE) of the Commissariat à l'Energie Atomique (CEA) has an atmospheric sampling station located at Montlhéry, $35 \mathrm{~km}$ southsouth-west of Paris and approximately 900 metres from a main road with high traffic levels, approximately 70,000 vehicles per day. The sampling station has a weather station recording the following data: wind speed and direction, precipitation, temperature, humidity; the wind rose established for 1998 is predominantly south-west, north-east. 


\section{SAMPLING APPARATUS AND FILTER SUPPORT}

The atmospheric particulates sampling apparatus (figure 1) used is the TGD 152 [1]. This apparatus type equips the French Particulate Radionuclides Stations installed ${ }^{1}$ as part of the world-wide network set up under the terms of the Comprehensive Test Ban Treaty (CTBT) [2] and intended to monitor atmospheric radioactivity (sensitivity: $10 \mu \mathrm{Bq} \cdot \mathrm{m}^{-3}$ for ${ }^{137} \mathrm{Cs}$ ). The high flow rate sampling apparatus can operate continuously under severe meteorological conditions. The horizontal sampling head is protected by an aluminium hood. The polypropylene filter, with a surface density of approximately $125 \mathrm{~g} \cdot \mathrm{m}^{-2}$ and effective dimensions $44 \times 44 \mathrm{~cm}$, is mounted in an air-tight manner on a calibrated grid support. The filter retention efficiency, measured experimentally, is greater than $93 \%$ for $0.15 \mu \mathrm{m}$ particles (French standard NF X 44011).

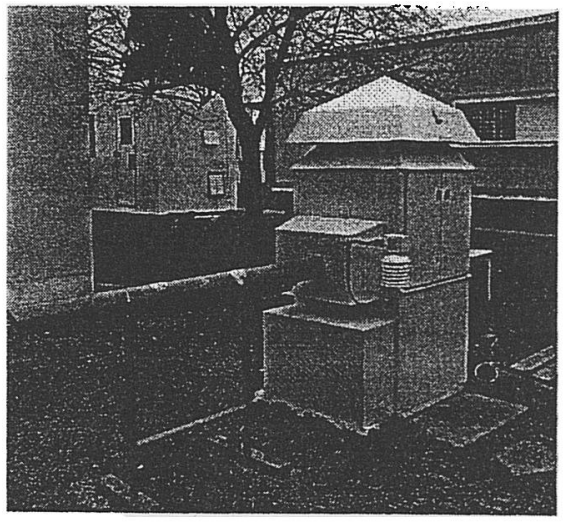

Figure 1: TGD 152 type sampler

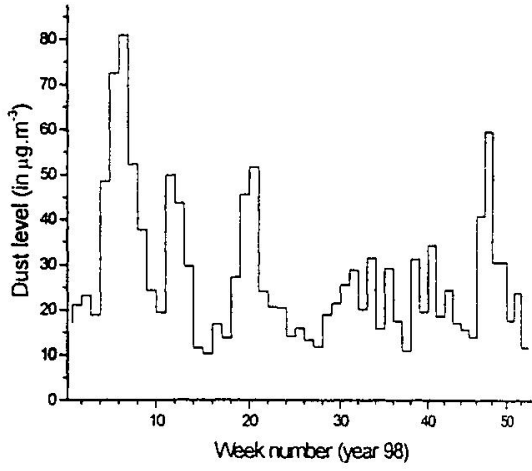

Figure 2. Dust concentration during year 98 observed at Montlhéry

For this study 54 weekly samples covering 1998 were taken; the weekly mean air flow rate, approximately $600 \mathrm{~m}^{3} \cdot \mathrm{h}^{-1}$, varied significantly according to the meteorological conditions observed during sampling; at certain times of the year, when the temperature inversion layer is low, the resulting atmospheric dust level is higher, whereas at other times heavy rainfall can cause a substantial decrease in the flow rate. During 1998 the minimum weekly mean flow rate $\left(440 \mathrm{~m}^{3} \cdot \mathrm{h}^{-1}\right)$ was obtained in winter.

\section{SAMPLE PREPARATION PROTOCOL}

The atmospheric particulate matter is sampled for one week, without particle-size cutoff. Each filter is oven-dried for 6 hours at $90^{\circ} \mathrm{C}$, then weighed on a precision balance, before it is placed in the sampling apparatus. On withdrawal, the aerosol-loaded filter is dried and weighed again; the mean weight loss after drying is about $4 \%$ of the total mass. The distribution of the aerosol masses on each weekly filtered air collected and measured in 1998 is shown in figure 2. It can be seen that, in winter, atmospheric dust levels in the Paris region can reach $80 \mu \mathrm{g} . \mathrm{m}^{-3}$ (weekly mean), a value that is slightly above the maximum annual limit adopted by the WHO $\left(60 \mu \mathrm{g} \cdot \mathrm{m}^{-3}\right)$. The filters are then compacted and reduced to ash in a programmable oven, using a protocol giving a slow temperature rise to $400^{\circ} \mathrm{C}$ over a period of 8 hours. In parallel, blank filters loaded with stable tracers (standards), prepared under the same conditions as the samples and undergoing the same protocol, were used to determine the calcination yield after INAA analysis for each element investigated in the atmospheric aerosols (except $\mathrm{Pb}$, analysed by ICP-MS after solubilization). After calcination, $50 \mathrm{mg}$ of sample were placed in a high-purity polyethylene container and heat-sealed. A set of blank filters, prepared under identical conditions to the samples, was analysed to identify and

\footnotetext{
'An operational station is installed on the island of Tahiti in the South Pacific.
} 
quantify impurities (major constituents: $\mathrm{Al}, \mathrm{Cl}, \mathrm{Cu}, \mathrm{Na}, \mathrm{K}$ ). In addition, for the same purpose, impurity concentrations of the empty container were determined (major constituents: $\mathrm{Al}, \mathrm{Mg}$ ).

\section{SAMPLE IRRADIATION AND INDUCED ACTIVITY MEASUREMENTS}

Although the INAA technique cannot quantify certain elements such as $\mathrm{Pb}, \mathrm{Hg}$ and $\mathrm{S}$ that are of particular interest as atmospheric pollutants, it is one of the most powerful non-destructive multi-element analysis techniques [3, 4], capable of determining some forty elements (lanthanides, rare earths, metals, $\mathrm{K}, \mathrm{Na}$, etc.).

The samples were irradiated using the HERMA pneumatic system installed on the periphery of the core of the OSIRIS reactor at the Centre d'Etudes Nucleaire at Saclay (CEA). This apparatus has a very fast transport system for shuttles carrying the container and the sampte; the transfer time between the reactor core and the gamma spectrometry laboratory located in a peripheral gallery is about 2 to 3 seconds, which enables detection and measurement of radioelements with half-lives of a few minutes.

Each samples was framed by two flux guides made of ultra-pure $\mathrm{Fe}$; experience has shown that, given the short duration of the irradiations, the neutron flux variation during the treatment of a set of samples can be considered negligible.

Two measurement procedures were used, depending on the elements to be analyzed. The short half-life radioelements $\left({ }^{28} \mathrm{Al},{ }^{52} \mathrm{~V},{ }^{66} \mathrm{Cu},{ }^{51} \mathrm{Ti},{ }^{80} \mathrm{Br},{ }^{38} \mathrm{Cl},{ }^{116 \mathrm{~m}} \mathrm{In},{ }^{57} \mathrm{Mn},{ }^{56} \mathrm{Mn}\right.$ ) were measured in the laboratory located close to the reactor by an HPGe detector, relative efficiency $30 \%$, with a collimator $100 \mathrm{~mm}$ thick and a $10 \mathrm{~mm}$ aperture. The sample was positioned automatically in front of the detector by the pneumatic system. The detector was calibrated using a multigamma $\left({ }^{152} \mathrm{Eu}\right)$ solution placed and dried in a container identical to the ones used for sample irradiation; the calibration was checked using a Monte-Carlo code, taking into account the corrections due to summing effects. An initial measurement $\left(\mathrm{T}_{0}\right)$ was made when the dead time of the acquisition electronics was less than $10 \%$. Three measurements were then made at $\mathrm{T}_{0}+10, \mathrm{~T}_{0}+20$ and $\mathrm{T}_{0}+30 \mathrm{~min}$.

The medium and long half-life radioelements $\left({ }^{46} \mathrm{Sc},{ }^{59} \mathrm{Fe},{ }^{51} \mathrm{Cr},{ }^{60} \mathrm{Co},{ }^{76} \mathrm{As}{ }_{152}{ }^{65} \mathrm{Zn},{ }_{169}{ }^{75} \mathrm{Se},{ }^{82} \mathrm{Br}\right.$, ${ }^{86} \mathrm{Rb},{ }^{99} \mathrm{Tc}(\mathrm{Mo}),{ }^{115} \mathrm{Cd},{ }^{122} \mathrm{Sb},{ }^{124} \mathrm{Sb},{ }^{131} \mathrm{Ba},{ }^{134} \mathrm{Cs},{ }^{140} \mathrm{La},{ }^{141} \mathrm{Ce},{ }^{110 \mathrm{~m}} \mathrm{Ag},{ }^{152} \mathrm{Eu},{ }^{169} \mathrm{Y},{ }^{24} \mathrm{Na}$, ${ }^{177} \mathrm{Lu},{ }^{181} \mathrm{Hf},{ }^{187} \mathrm{~W},{ }^{198} \mathrm{Au},{ }^{233} \mathrm{~Pa}(\mathrm{Th}),{ }^{42} \mathrm{~K}$ ) were made in our laboratory at Bruyères le Châtel using HPGe detectors with relative efficiencies of 30 to $50 \%$. The detector was calibrated using a multi-element gamma solution [5] in the same geometry as the sample. All the measurements were made at a distance of $10 \mathrm{~cm}$ from the detector to minimize gamma summing effects. An initial measurement was made 1 day after irradiation $\left(T_{0}\right)$, then further measurements at $T_{0}+5, T_{0}+20$ days.

The element concentrations, allowing for experimental conditions and including corrections for dead time and for decay during acquisition, are calculated (ng. $\mathrm{m}^{-3}$ ) using the customary formula for activation analysis [13].

The gamma spectra were processed using the GW software [6]. All the nuclear data (thermal neutron absorption cross-sections, gamma emission intensities) were taken from references [7, 8], and the elemental isotopic abundances were taken from reference [9].

The Minimum Detectable Concentration (MDC) calculation was based on the definition of Currie [10] and complies with the expressions defined by the international organization overseeing the CTBT [2].

\section{ATMOSPHERIC POLLUTION MONITORING IN THE PARIS REGION}

AIRPARIF [11], the entity responsible for air quality monitoring in the Paris region, has three types of station for measuring the main primary atmospheric pollutants $\left(\mathrm{CO}, \mathrm{NO}, \mathrm{NO}_{2}, \mathrm{O}_{3}\right.$, $\mathrm{SO}_{2}$ ) covering a radius of approximately $100 \mathrm{~km}$ around Paris:

The concentrations of primary pollutants measured by an urban background station (located in Paris, 500 metres from the Place d'Italie), representative of climatic events at the scale of the Paris region, were compared with the levels in the atmosphere of the stable elements determined by this study.

For this purpose the daily measurements made by AIRPARIF in 1998 have been matched to the corresponding weeks of TGD 152 atmospheric sampling. 
$M D C_{\left(\text {mass } / \mathrm{m}^{3}\right)}=\frac{K_{a} \times 2.71+4.65 \sqrt{\sum_{\text {ROI }} \text { count }_{i}}}{t_{m} \times \varepsilon_{a b s} \times V_{a} \times K_{s} \times K_{w} \times K_{c}}$

where:

$\mathrm{ROI}$ is defined as \pm 1.25 Full Width Half Maximum on either side of the hypothetical peak

$\mathrm{K}_{\mathrm{a}}, \mathrm{K}_{\mathrm{s}}, \mathrm{K}_{\mathrm{w}}, \mathrm{K}_{\mathrm{c}}$ : respectively factors related to the conversion mass $/ \mathrm{Bq}$, decay corrections during activation time, between end of activation and acquisition start, during acquisition time

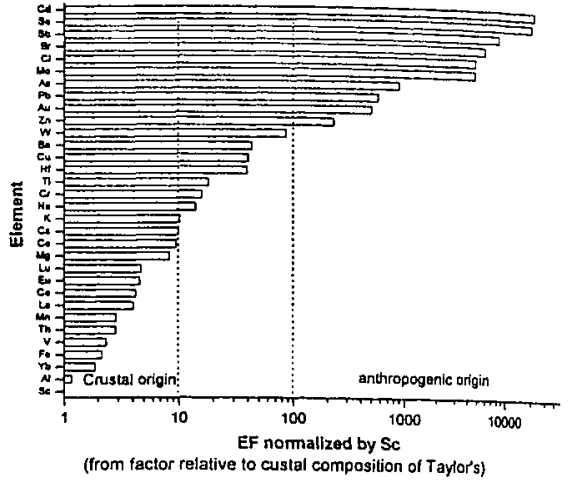

Figure. 3. Enrichment factors related to TSP

\section{RESULTS AND DISCUSSION}

A certain number of elements present in the aerosols are used as markers of certain sources of atmospheric pollution, of anthropogenic or natural origin. The various sources of urban pollution (main elements $\mathrm{As}, \mathrm{Se}, \mathrm{Zn}, \mathrm{Sb}$ ) and the natural sources, derived essentially from crustal material and the ocean, (main elements $\mathrm{Al}, \mathrm{Cl}, \mathrm{Fe}, \mathrm{La}, \mathrm{Mn}, \mathrm{Na}, \mathrm{Ce}, \mathrm{Sm}$ ) are listed in reference [18].

An effective approach for revealing any atmospheric pollution of anthropogenic origin consists in calculating an enrichment factor (EF) for each element, defined as the ratio of the element of interest in the sample to a reference element in the sample $(\mathrm{Xi} / \mathrm{Ci})_{\text {SAMPLE }}$ divided by the same ratio in a reference material $(\mathrm{Xi} / \mathrm{Ci})_{\mathrm{REF}}$. In this work the table of crustal abundance given by Taylor [12] was used, with respect to Sc as the reference element because of its low volatility and lack of anthropogenic sources. The mean enrichment factor for each stable element, calculated from the 54 weekly atmospheric samples taken in 1998, is shown in figure 3 .

The mean enrichment factors show a very wide range of variation $\left(1\right.$ to $\left.10^{4}\right)$. The hypothesis of emission sources of anthropogenic origin is highly probable for certain elements showing an EF greater than $10^{2}$ (Cd, Se, Sb, $\left.\mathrm{Br}, \mathrm{Cl}, \mathrm{As}, \mathrm{Pb}, \mathrm{Mo}, \mathrm{Au}, \mathrm{Zn}\right)$. Low enrichment factors, below 10, were observed for certain elements such as $\mathrm{Al}, \mathrm{Co}, \mathrm{Cs}, \mathrm{K}, \mathrm{Mg}, \mathrm{Mn}, \mathrm{Th}, \mathrm{V}$ and the rare earths; it can be assumed that these elements correspond to the redispersion of materials from superficial layers of the ground in the investigated area. A few elements have moderate enrichment ( $\mathrm{Cr}, \mathrm{Na}, \mathrm{Ti}, \mathrm{Ba}, \mathrm{Cu}, \mathrm{W}, \mathrm{Hf}$ ).

These results can be interpreted by considering a process of deposition of atmospheric aerosols enriched with stable elements under the effect of favourable climatic conditions. It should be noted that the concentration of the element $S c(10 \mathrm{ppm})$, used as reference for the enrichment factor calculations, is compatible with the value given by Taylor (20 ppm) [12].

The trace element concentrations determined in TSP and presented in this work are in all cases equivalent to the levels found in industrialized suburban areas of the major European cities. The mean concentrations (1998) of stable elements measured in the Paris suburbs, expressed in $\mathrm{ng}^{-3}$, the values published by several authors $[13,14,15,16]$ for different cities in Europe and in Asia, and the minima and maxima for the USA are given in table 1. The mean concentrations measured near Paris are characteristic of the major industrial cities and give an idea, despite the wide seasonal variation, of the total quantities of trace elements present in atmospheric aerosols in urban areas and of the nature of the main pollutants; these data, coupled with other parameters such as meteorological data, are essential clues for identifying the emission sources. 
The mean $\mathrm{Br} / \mathrm{Na}$ ratio calculated for $1998(0.045)$ is an order of magnitude greater than the oceanic ratio $(0.0062)$ [17]; this result indicates a local emission source for the element $\mathrm{Na}$; the probable origin is an incinerator located $10 \mathrm{~km}$ from the sampling point, $\mathrm{Na}$ and $\mathrm{Cl}$ being characteristic markers of this type of pollution [18].

The $\mathrm{Cl} / \mathrm{Pb}$ ratio is an indication of fresh particles emitted in the exhaust by engines burning petrol; this ratio is about 0.14 [19]. However, it should be noted that this ratio can be significantly different in France depending on the type of fuel produced. In this work the Cl/Br ratio was found to be 91 , a very high value, which supports the hypothesis of the incinerator as potential emission source.

The $\mathrm{Br} / \mathrm{Pb}$ ratio, a characteristic of fuel quality, can vary from 0.28 to 0.47 [19]. The mean annual $\mathrm{Br} / \mathrm{Pb}$ ratio found in this work is close to 2 ; this result, much higher than the expected value considering the sampling apparatus is located 800 metres from a main road with heavy traffic, may indicate the involvement of a substantial emission source for $\mathrm{Br}$, independent of the one related to road traffic.

In contrast the high enrichment factors for elements $\mathrm{Cd}, \mathrm{Pb}$ and $\mathrm{Sb}$ can be assumed to indicate pollution for which the main emission source is road traffic; other elements $(\mathrm{Cu}, \mathrm{Ce}, \mathrm{La}$, etc.) could have the same origin, as suggested by Huang et al. [20].

The elements As and Se, in trace amounts in the atmospheric aerosols but showing high EF values, could originate in the use of fossil fuels (district heating, etc.).

The distribution of the concentrations of three heavy elements (Mo, $\mathrm{Sb}$ and $\mathrm{Pb}$ ), characterized by high potential toxicity, in the 54 weekly atmospheric samples collected in 1998 has been compared with the variation in a primary pollutant $\left(\mathrm{SO}_{2}\right)$ measured by AIRPARIF over the same period. There is high seasonal variability; the maximum concentrations are observed in winter periods that favour temperature inversions and climatic episodes involving anticyclonic stability and lack of wind. Moreover, there is considerable similarity between the annual variation of primary pollutants $\left(\mathrm{SO}_{2}, \mathrm{NO}\right.$, etc.) and that of trace elements in the atmospheric particulates; as an example, analysis of the covariance of the data for $\mathrm{SO}_{2}$ and for the metallic elements gives a correlation coefficient $\left(\mathrm{C}_{\mathrm{F}}\right)$ close to 0:7. This can be explained by the fact that the stable particulate pollutants and the chemical pollutants come from emission sources that are very probably of different origins, but are produced in a diffuse manner, thus obeying the same dispersion rules dependent on the same climatic conditions. This hypothesis is plausible, since no correlation is observed between variation in $\mathrm{Pb}$ and $\mathrm{Sb}$ concentrations and variation in road traffic in the immediate vicinity of the sampling apparatus.

Considering the variation during the year of the concentrations of certain elements of nonanthropogenic origin no correlation with the variation of primary pollutants is observed; this is a general trend for all the elements quantified in the atmospheric aerosols showing a low EF value and mainly of crustal origin. The low measured concentrations of these elements and the fact that the sampling apparatus is installed in a semi-urban area suggests a nearby origin, related to natural redispersion phenomena.

The annual variation of certain elements with high $\mathrm{EF}$ values exhibit poor correlation with the variation of primary pollutants, which might indicate the presence of a point source close to the sampling area.

\section{CONCLUSION}

The characterization of trace elements in suspended particulate matter in major industrial cities has recently become a subject of research, since the public authorities became aware of the absence or deficit of data on possible toxicological and physiological impacts of certain elements on health. Furthermore, standards for maximum permitted concentrations in the atmosphere, including for the aerosol fraction smaller than $2.5 \mu \mathrm{m}$, the most harmful to the human respiratory system, are now being introduced. Although the data provided by this study concern only the total atmospheric suspended particulates (TSP), the entire particle-size range was included, as the efficiency of the filter medium remains high down to submicron particle sizes. However, the relationship between the analysis and the particle size 


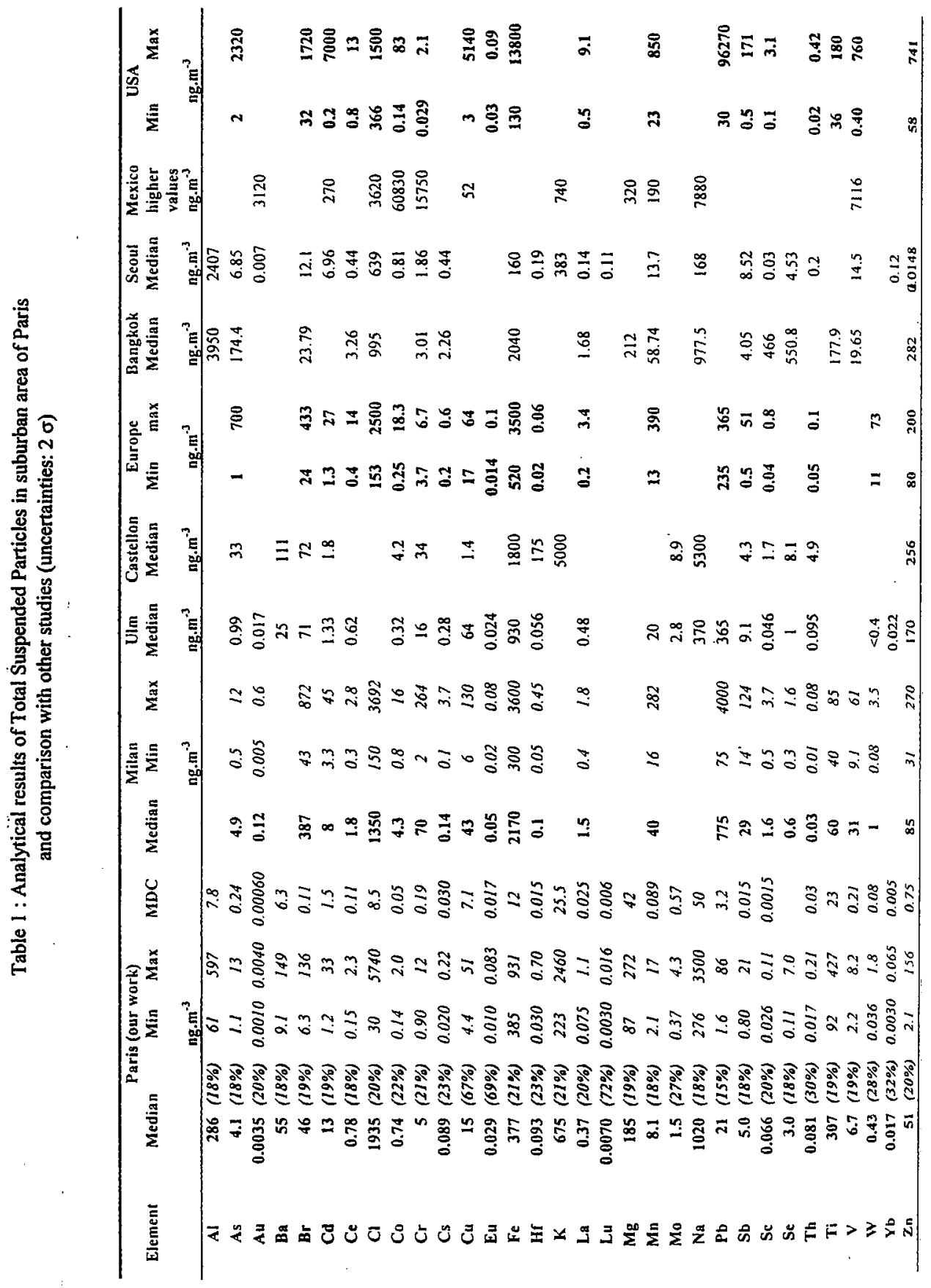


class was not studied. The nature of the elements and the concentrations detected in the atmosphere during 1998 identify the major anthropogenic pollutants and show their seasonal variations. These data provide a guide for further investigation of the impact on man. The results obtained could be used as reference indicators for evaluating the long-term overall variation of atmospheric pollution in the Paris region, particularly the heavy metal levels.

Furthermore, in addition to the measurements provided by the type of study described here, it is necessary to set up collaborations with the various protagonists concerned to a greater or lesser extent by urban pollution in order to obtain the most complete possible synthesis of the available data, in particular those relating to the emissions of the various industrial activities, which are rarely published. Knowledge of these data, coupled with atmospheric modelling taking into account local weather, should enable more precise determination of the origin of emission sources for the major pollutants.

This study has also shown that neutron activation analysis remains a powerful, nondestructive, multi-element analysis method, with a measurement sensitivity that remains acceptable for this type of study. Nevertheless, knowledge of the atmospheric concentrations of certain elements $(\mathrm{Pb}, \mathrm{Hg}, \mathrm{S})$ that are of particular interest in terms of their impact on man necessitate the use of other techniques in addition to neutron activation (ICP-MS, AAS, etc.).

\section{Acknowledgements}

The authors wish greatly to thanks J.Aupiais, F. Raynaud, F. Leprince and S. Mietlicki (AIRPARIF) for their participation in this work

\section{References}

[1] Société française d'ingénierie 36 Boulevard des Océans 13009 Marseille S.F.I@wanadoo.fr

[2] J.Schulze, M.Auer, Rwerzi App. Radia. and Isot. 52 (2000) p23-30

[ 3 S.Sarmani, I.Abugassa, A.Hamzah J. of Radioanal. and Nucl. Chem. Vol.234 Nos 1-2 (1998) p 17-20

[4] R.Djingova, JU:Ivanova, I.Kuleff J. of Radioanal. Chem, Vol.237, Nos 1-2 (1998) p25-34

[5] AEA Technologie France F-91955 Courtaboeuf Cedex

[6] Westmeir Gesellschaft für Kernspektrometrie mbH - Beratung Software, Geräte Möller Weg 82 D-W 3557 Ebsdorfergrund - Mölln

[7] Blaauw, Interfacultair Reactor Institut van de Technische Universiteit Delft (1996)

[8] Ertmann G. Neutron activation Tables Kernchemie in Einzeldarstellangen Vol.6 Verlagchemie New York (1976)

[9] VG De Bievre P; Branes I.L Handbook of Chem. and Phys. $73^{\text {rd }}$ Edition CRC Press (1992) p $11-132$

[10] L.A Currie, J. of Radioanal. and Nucl. Chem., (1968) p40 586

[11] AIRPARIF Rapport d'activité (1998) 108 pages

[12] S.R.Taylor, Geochem. and Cosmochem.. Acta (1972) 281973

[13] Y.S.Chung, Y.J Chung, E.S.Jeong, S.Y.Cho, analysis J. of Radioanal. Nucl. Chem., Vol.217, N¹(1997) p83-89

[14] M.Gallorini, P.A.Borrini, M.Bonardi, A.Rolla, J. of Radioanal. and Nucl. Chem., Vol.235, Nos 1-2 (1998) p241-247

[15] X.Querol, A.Alastuey, A.Lopez-Soler \& Al, J. of Anal.. And Nucl. Chem. (1997) 357 p934-940

[16] V.Krivan, KP.Egger, Z Analytical Chemistry (1986) 325 p41-49

117] S.Nouchpramool, T.Sumitra, V.Leenanuphunt, International Conference (NAMLS) Beijing China October 26-30 (1998): 5 pages

[18] JK.Gone, I.Olmez, M.R.Ames, J. of Radioanal. and Nucl. Chem., Vol 244, No 1 (2000) p133-139

[19] C.Ozben, B.Belin, H.Güven, J. of Radioanal. and Nucl. Chem.. Vol 238. Nos 1-2 (1998) p101-104

[20] X.Huang, I.Olmez, NK.Aras Atmos. Environ. (1994) 28 N8 p1385-1391 